\title{
THE ROLE OF FAMILY INTERVENTION IN EARLY DETECTION OF CONGENITAL DEAFNESS: A CASE STUDY
}

\author{
Alif Sholehen ${ }^{1}$, Fajrinka Pralampito ${ }^{1}$, Antonius Galih ${ }^{1}$, Akbar Ghaus ${ }^{1}$, Andi Airina ${ }^{1}$, \\ Nyilo Purnami* ${ }^{2}$ (D)
}

${ }^{1}$ Faculty of Medicine, Universitas Airlangga, Indonesia ${ }^{2}$ Department of Ear Nose Throat (ENT) - Head Neck Surgery, Faculty of Medicine, Universitas Airlangga - Dr. Soetomo General Academic Hospital Surabaya, Indonesia

\begin{abstract}
Congenital deafness is a hearing loss disorder that occurs at birth and is one of the disorders that can cause complications when it is not treated.1 Children with hearing loss will face difficulties such as poor development outcomes, including poor speech and language skills and face difficulties with cognition and social-emotional interactions. Early intervention has been proven to be one of the most important factors leading to good outcomes for children with congenital hearing loss. 2 This case study is intended to highlight the importance of early case detections, early interventions and how family support plays a crucial role in the development of children with hearing loss. With the support of her family, Ms. DRP has gone through several speech and hearing therapies since her surgery and has proven to have an above-average linguistic abilities, showing that early problem detection does not hinder the development and achievement of children with congenital hearing loss.
\end{abstract}

\section{ARTICLE HISTORY}

Received: June 20, 2020

Revised: July 9, 2020

Accepted: August 18, 2020

Published: August 30, 2020

(Online)

doi: $10.20473 /$ jcmphr.v1i2.21702

\section{KEYWORDS}

Congenital deafness, family support, early detection

\section{CORRESPONDING}

\section{AUTHOR}

Nyilo Purnami

$\bowtie$ nyilo@fk.unair.ac.id

Department of Ear Nose Throat - Head Neck Surgery, Faculty of Medicine, Universitas Airlangga - RSUD Dr. Soetomo Surabaya, Jl. Mayjen Prof. Dr. Moestopo No. 6-8, Airlangga, Gubeng Surabaya, Indonesia

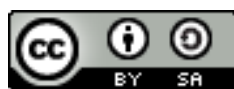

\section{INTRODUCTION}

Congenital deafness is a type of hearing loss that appears at birth and is one of the most common disorders. 1 The factors that affect before, during, and after pregnancy are several causes of congenital deafness. ${ }^{3}$ Deafness can be divided into two, namely partial deafness (hearing impaired) or total deafness (deaf). Partial deafness is a state of hearing impairment but can still be used to communicate with or without the aid of hearing aids, while total deafness is a state of hearing function that is so disturbed that it cannot communicate properly. Congenital deafness is divided into genetic heredity (heredity) and non-genetic. ${ }^{4}$

Most of the hearing loss experienced by children since birth has no clear risk factors so that it is often not detected by parents. 310 cases $(82.23 \%)$ of hearing loss in children had no known risk factors. Early detection is very important to avoid late diagnosis and interventions that can impact children's speaking and language skills in the long term. Several hearing tests for early detection have been recommended by 
the Newborn Hearing Screening Program (NHSP) including the Otoacoustic Emissions (OAE) and Brainstem Evoked Response Audiometry (BERA). This examination is the gold standard for early detection of hearing loss in infants and children. Sensorineural deafness is a type of deafness that is often encountered, ranging from severe to very severe, which can affect both ears (bilateral). Based on a retrospective descriptive study conducted at Dr. Soetomo Surabaya, most cases experienced bilateral sensorineural hearing loss as many as 357 patients $(94.69 \%)$. The majority of patients experienced severe hearing loss, namely 329 patients $(87.287 \%)$ of a total of 377 patients. $^{5}$

Early symptoms are usually difficult to detect or recognize. Usually, parents only become aware of hearing loss in children when there is no response to loud sounds or not / late speaking. Therefore, the importance of stimulus or information stimulation from parents is to determine the child's response to sounds in the home environment, vocalization abilities and how to pronounce words to prevent deterioration of hearing function. ${ }^{6}$

Hearing loss such as congenital deafness experienced by children since birth is closely related to abnormalities in the development of speech and language in children. Based on the data of a retrospective descriptive study conducted at Dr. Soetomo Surabaya through the collection of data on subjects for the 20112013 period, there were 377 patients $(68 \%)$ with sensorineural hearing loss from a total of 552 babies and children. The highest age group for sensorineural hearing loss was the age group of 12 to 36 months with 237 patients $(62.86 \%)$ and most of them were male, namely 199 patients $(52.79 \%)$. There are still many infants and children who have sensorineural hearing loss with varying degrees of severity, but the degree of profound hearing loss is the most dominant. Unknown risk factors are the basis for the importance of early detection of hearing loss experienced by infants and children so that early intervention can be carried out immediately to prevent abnormalities in speech and language development. ${ }^{5}$

Hearing loss is a health problem that requires special attention. Based on the Universal Newborn Hearing Screening (UNHS), the incidence of hearing loss in infants and children will be much higher, namely, around 1.64 out of 1000 children born alive have congenital deafness. 1 in 1000 live births are deaf bilaterally, and 0.64 out of 1000 live births are unilateral. In developed countries, the congenital deafness rate ranges from $0.1-0.3 \%$ live births. 1,6,7 Meanwhile, in Indonesia, based on a survey conducted by the Ministry of Health in 7 provinces in 1994 1996 , it was $0.1 \%$

One of the risk factors for deafness in infants and children includes family history, deformities of the head and face, and prenatal, perinatal, and postnatal history such as preterm birth, low birth weight ( $<1500$ grams), actions with the use of tools in the process. birth (vacuum extraction, forceps), hyperbilirubinemia, asphyxia (born indirectly crying), and brain hypoxia if the Apgar value is $<5$ in the first 5 minutes.9 (Gomella 2004). According to the Academy American Joint Committee on Infant Hearing Statement (2007), in infants aged 0-28 days if found the following factors should be suspected because they are possible causes of hearing loss: 1) 
Family history of deafness from birth, 2) Prenatal infection; TORCH, 3) Anatomical abnormalities in the head and neck, 4) Syndrome associated with congenital deafness, 5) Low birth weight (LBW $<1500$ grams), 6) Bacterial meningitis, 7) Hyperbilirubinemia (yellow baby) requiring exchange transfusion, 8) Severe asphyxia, 9) Administration of ototoxic drugs, 10) Using a breathing apparatus / mechanical ventilation for more than 5 days (ICU) . ${ }^{10}$

\section{CASE REPORT}

Ms. DRP, 19 years old, presented with a complaint of hearing loss. This incident started at the age of 1 year. The patient's mother did not realize that her child had decreased hearing and did not know that the hearing loss was sudden or got worse over time. The patient's mother only realized that her child did not respond when called his name. The patient did not respond to being summoned either through stimulation to the right or left ear. According to the mother, the hearing loss experienced by her child is persistent and does not change over time and never gets better because the child does not respond at all when called his name. Initially, the patient's mother thought that maybe because she was still a baby, but over time the child did not respond at all when he was called his name. History of trauma is refuted. There is no fever. No headache. No nausea vomiting. History of decreased consciousness is refuted. The patient's bowel and bladder were within normal limits. The patient's diet is good 3 times a day, but several times the patient is late in eating due to his busy schedule during social service activities and fashion competitions. Currently, the patient is not taking any drugs.
Medical History, at the age of 1 year, parents checked their children to Dr. Soetomo Surabaya and the doctor said that his son was deaf. Parents did not believe in their child's illness, so parents sought a second opinion by having their child checked out at Cipto Hospital Jakarta. When brought to RSCM, the doctor said that his son had decreased hearing in both ears and said there was damage to his child's ear nerves. The patient has undergone several hearing tests 3 times including tests that have been performed including BERA, with results of $110 \mathrm{~dB}$ in the left and right ears.

The child was then brought back by his parents to RSUD Dr. Soetomo Surabaya and it was recommended to have implants installed at the age of 1 year, but the family refused. The family refused out of fear that their child would have to undergo surgery for implants. The family finally decided to help their child's hearing through the installation of pocket hearing aids (ABD). The patient's family changed the hearing aid used by the child several times and also took the child to alternative therapy, but the child's complaints did not improve and the child still did not respond. Because the child's complaints did not improve, the family decided to have implants installed when the child was 10 years old, namely in 2010. The implant was placed in Jakarta and was done on the right ear. Until now, the left ear was not implanted. However, the patient's left ear uses a hearing aid. After implant placement. After implant hearing, complaints began to improve and the child began to respond. In addition to implant placement, the child has also undergone speech therapy and auditory stimulation done several times a week to date. 
Past medical history (pediatric history), at the age of 1 day after birth, the patient was taken to the nursery room and given bottle milk by the nursing nurse. The nurse was careless when giving milk to the patient so that she was choking. Shortly after the patient chokes on milk, the patient's skin suddenly turns blue and has difficulty breathing. The patient's father took him to another hospital and underwent treatment in the hospital for 40 days. The patient receives daily oxygen therapy with a large volume of oxygen. The doctor said that this oxygen administration could affect the patient's eyes and ears. After 40 days of treatment, the patient was discharged from the hospital but was not checked for his hearing. 7 days after being discharged from the hospital, the patient had complaints of bloody bowel movements. According to doctors, the complaint was due to excessive milk feeding. The patient underwent several days of treatment in the hospital. Besides, the patient was hospitalized for dengue fever. The patient is treated for several days. Currently, in the last few days, patients often experience stomach pain due to gastritis due to their busy schedules, so they often eat late. Deformities of the head and face, including abnormalities in the ear lobe and ear canal, were denied. During pregnancy, the mother routinely checks her pregnancy to an obstetrician. History of seizures, fever, decreased consciousness during pregnancy is denied. The use of drugs during pregnancy is denied except for blood-boosting supplements. Before, during, and after pregnancy, none of the family members kept pets. Besides, the history of pregnancy and birth of the patient's sister was normal for 9 months and 2 days.
Born History, the patient was born at 8 months of pregnancy (premature), was born normally, birth weight 2500 grams, immediately cried loudly, was not blue, but had yellow and was treated in an incubator. The patient underwent phototherapy at a hospital in Surabaya. The history of exchange transfusion was refuted.

Nutritional history, the patient consumed premature milk for several months and was replaced by soy milk by the pediatrician because it was said to be allergic to cow's milk. The patient did not receive exclusive breastfeeding and only received breast milk for 3 months. From the age of 6 months, the patient started complementary foods in the form of mother-made team rice. Immunization history, complete basic immunization to measles at 9 months of age, and additional meningococcal immunization.

Family history, no family experienced similar complaints. History of DM and HT in parents was denied. Patient. the patient's older brother and mother had asthma which was triggered primarily by fatigue and dust. Obtained a family history of hearing loss since childhood, namely children of Pakde, but the patient's parents do not know in detail the disease experienced. The test obtained was a BERA examination with a result of $110 \mathrm{~dB}$ in both right and left ears (complete hearing loss).

\section{DISCUSSION}

In this case, the main complaint was obtained from heteroanamnesis, namely, the parents realized that the child was insufficient or did not respond to loud sounds, as well as when he was called when he was a child. Another history of the child being unable to respond 
to being called by his parents or the sound near the patient at the age of 1 year, with speech development delays and hearing loss, the patient was brought to the doctor. Delay in a speech in children can be caused by hearing loss, especially if the child at 12 months of age is not able to babble or imitate, and at 18 months of age cannot say one meaningful word. $^{10}$ In hearing loss, a common complaint from parents is that the child is late speaking, does not respond when called or there is a sound/sound. ${ }^{11}$

Based on the patient's history and examination, no abnormalities were found during the prenatal period. When pregnancy, the patient's mother did not get other diseases and disorders during pregnancy, the patient's mother routinely went to the obstetrician and received complete immunization. Congenital infection is an important risk factor; congenital cytomegalovirus (CMV) infection is the most common non-genetic cause of sensorineural hearing loss (SNHL). And in countries without a rubella vaccination program, congenital rubella infection is the leading cause of congenital deafness. ${ }^{12}$ From a study conducted by Grosse, Ross, and Dollard in 2008, approximately $14 \%$ of children with congenital CMV infection have an impairment. sensorineural hearing loss (SNHL) and 3-5\% with moderate to severe bilateral sensorineural hearing loss $(\mathrm{SNHL}){ }^{13}$ Among all children with moderate to severe bilateral SNHL, it is estimated that $15-20 \%$ of cases are due to congenital CMV infection. Apart from CMV, Rubella is also one of the viruses that cause congenital deafness. Based on research in America, it was found that $70 \%$ of adult women are infected with the Rubella virus. If the infection occurs in the first trimester, it is highly likely that the fetus will be infected and cause Congenital Rubella Syndrome, abortion, and severe birth defects. The triad of Congenital Rubella Syndrome symptoms are sensorineural deafness, congenital cataracts, to heart problems. ${ }^{14}$

The neonatal history showed preterm birth, prolonged use of incubators and oxygen, presence of jaundice, history of cyanosis, and birth weight of 2500 grams. Some of these are risk factors for congenital deafness. ${ }^{15}$ A study in the UK showed a link between SNHL (Sensorineural Hearing Loss) and prematurity. SNHL is the highest disability for premature infants either through the mechanism of prolonged hypoxia, acidosis or due to high levels of bilirubin. ${ }^{16}$ Another study in Edmonton, Canada showed that prematurity was a predictor of permanent hearing loss in most of the sample. Hearing loss is mainly caused by prolonged oxygen supplementation, which is mainly given to preterm infants. ${ }^{17}$

Other risk factors include neonates admitted to the intensive care unit (NICU), with an increased prevalence of hearing loss due to gestational age and low birth weight $(1.2-7.5 \%$ in preterm infants born at 24-31 weeks and 1, 4\% - 4.8\% in infants weighing 750-1500g). Provided medical intervention (such as mechanical ventilation, venous access, and use of aminoglycoside antibiotics) in the neonatal intensive care unit (NICU) increases the likelihood of hearing loss in neonates. Length of stay over 12 days and a history of treatment with high-frequency ventilation has also been identified as independent risk factors for neonatal hearing loss. 
Hearing tests for babies include automated auditory brainstem response (ABR) and transient evoked otoacoustic emissions (TEOAE). Based on the results of the supporting tests used, namely the BERA examination, the results obtained were 110 $\mathrm{dB}$ in the left ear and right ear. According to $\mathrm{WHO}$, a test result that exceeds $81 \mathrm{~dB}$ is included in the category of profound hearing loss. ${ }^{18}$ If the earlier a child is identified as having hearing loss and the earlier he receives support, the more likely the child is to learn spoken language and the lower the possibility of adverse effects from the disorder. hearing. The Joint Committee on Infant Hearing recommends that all children with hearing loss should receive intervention by the age of six months. ${ }^{10}$ Research shows that children who are born deaf or who lose hearing very early in life and continue to receive appropriate interventions before age 6 months can be equivalent to normal children in terms of language development by the time they are five years old. ${ }^{15}$

Early intervention programs and newborn hearing screening programs (based on physiological methods) that focus on early intervention, ideally starting before 6 months of age; family support, including parental guidance and counseling; hearing rehabilitation through hearing aids and cochlear implants; appropriate therapeutic and communication options. ${ }^{20}$ Newborn hearing screening programs should follow a family-centered approach, in which families are empowered to make decisions for their children. In this case, family support is very strong from the start until now the patient can be independent and have activities like normal people. Early recognition of language provides many benefits, in the form of rehabilitation for verbal communication (such as auditory- verbal and auditory-oral therapy) and alternative means of communication, including sign language, bilingual materials, and lipreading approaches. ${ }^{21}$

\section{CONCLUSION}

The development of Ms. DRP is much better than the previous condition before cochlear implant placement. Even though only the left ear has a cochlear implant, it does not make a social function of Ms. DRP is compromised. Ms. DRP remains active in socializing and achieves in their preferred fields. Ms. DRP shows the intention to continue to grow by following the routine therapy he is undergoing. Support from a good family from both parents who always accompany Ms. DRP to participate in therapy and control to a doctor if there are complaints. Children born with congenital hearing loss often do not achieve real linguistic success and progress. DRP is very proud. This case is particularly valuable in the field of speech and language development as it demonstrates the importance of early identification, family support, and early intervention in infants and children born with hearing loss. Early hearing loss is a widespread problem that can have serious consequences for language skills, speech, behavior, and socio-emotional health. However, if it can be identified early and treated immediately, children with hearing loss can gain better speaking and language skills. 


\section{REFERENCES}

1. Faundes V, Pardo R, Castillo Taucher $\mathrm{S}$. Genética de la sordera congénita. 2012. Medicina Clínica 139(10), 446451.

2. Vohr B, Jodoin-Krauzyk J, Tucker R, Johnson M, Topol D, Ahlgren M. 2008. Early Language Outcomes of Early-Identified Infants With Permanent Hearing Loss at 12 to 16 Months of Age. Pediatrics 122(3), 535-544.

3. Steer C, Golding J, Bolton P. 2010. Traits Contributing to the Autistic Spectrum. PLoS ONE 5(9), e12633.

4. Genetics in Medicine. 2002. Genetics Evaluation Guidelines for the Etiologic Diagnosis of Congenital Hearing Loss. 4(3), 162-171.

5. Purnami N, Dipta C, Rahman M. 2018. Characteristics of infants and young children with sensorineural hearing loss in Dr. Soetomo Hospital. Oto Rhino Laryngologica Indonesiana 48(1), 11.

6. Gürtler N, Lalwani A. 2002. Etiology of syndromic and nonsyndromic sensorineural hearing loss. Otolaryngologic Clinics of North America 35(4), 891-908.

7. Nugroho D. 2013. Kemampuan Auditorik Anak Tuli Kongenital Derajat Sangat Berat dengan dan Tanpa Bantu Alat Dengar. Medica Hospitalia : Journal of Clinical Medicine 1(2).

8. Soetirto I, Hendarmin H, Bashiruddin J. Gangguan pendengaran (tuli). in Soepardi EA, Iskandar N, Bashiruddin J, Restuti RD, editor. 2017. Buku ajar ilmu kesehatan telinga, hidung, tenggorok, kepala dan leher. Edisi ke-6. Jakarta: Balai Penerbit FKUI, 10-22.

9. Bany-Mohammed F, Eyal F, Gomella T. 2004. Gomella's Neonatology-management, procedures, on-call problems, diseases, and drugs. 5 th ed.
New York: Lange Medical Books/McGrawHill.

10. Pediatrics. 2007. Year 2007 Position Statement: Principles and Guidelines for Early Hearing Detection and Intervention Programs. Available from:

https://pubmed.ncbi.nlm.nih.gov/179 08777/ [Accessed 20 May 2020].

11. Pediatric Rubella: Background, Pathophysiology, Epidemiology. Available from: https://emedicine.medscape.com/arti cle/968523-overview [Accessed 20 May 2020].

12. Korver, A., Smith, R., Van Camp, G., Schleiss, M., Bitner-Glindzicz, M., Lustig, L., Usami, S. and Boudewyns, A. 2017. Congenital hearing loss. Nature Reviews Disease Primers 3(1).

13. Grosse, S., Ross, D. and Dollard, S. 2008Congenital cytomegalovirus (CMV) infection as a cause of permanent bilateral hearing loss: A quantitative assessment. Journal of Clinical Virology 41(2), 57-62.

14. Pratiningrum, Moriko., Purnami, Nyilo. 2011. Ketulian Pada Sindroma Rubella Kongenital (Laporan dua kasus). Surabaya: SMF Ilmu Kesehatan THT-KL FK Universitas Airlangga-RSUD Dr. Soetomo Surabaya.

15. Pengurus Pusat PERHATI-KL. 2016. Panduan Praktik Klinis, Panduan Praktik Klinis Tindakan, Clinical Pathway di bidang telinga hidung tenggorok - kepala leher. 2nd ed. Jakarta: Pengurus Pusat PERHATIKL.

16. Marlow E. 2000. Sensorineural hearing loss and prematurity. Archives of Disease in Childhood Fetal and Neonatal Edition 82(2), $141 \mathrm{~F}-144$.

17. Robertson C, Howarth T, Bork D, Dinu I. 2009. Permanent Bilateral Sensory and Neural Hearing Loss of Children After Neonatal Intensive 
Care Because of Extreme Prematurity: A Thirty-Year Study. PEDIATRICS 123(5), e797-e807.

18. World Health Organization. 2020. Primary ear and hearing care. Available from: https://www.who.int/pbd/deafness/ac tivities/hearing_care/en/. [Accessed 20 May 2020].

19. Yoshinaga-Itano C, Seday AL, Coulter DK, Mehl AL. 1998. Language of early- and lateridentified children with hearing loss. Pediatrics 102(5), 1161-71.

20. Holzinger D, Fellinger J, Beitel C. 2011. Early onset of family centred intervention predicts language outcomes in children with hearing loss. International Journal of Pediatric Otorhinolaryngology 75(2), 256-260. 